\title{
The Adaptation of Language Learning Curiosity Scale into Turkish Language
}

\author{
Cavide DEMIRCI' ${ }^{1}$, Mehmet AKCAALAN ${ }^{2}$
}

Article History:

Received 04.03.2021

Receivedin revised form

21.11.2021

Accepted

Available online 01.01.2022

\begin{abstract}
The purpose of this study is to test a version of the original language-learning curiosity scale (LLCS) adapted for the Turkish language and culture. The concept of curiosity has been explained in many types and scopes. Language curiosity comprises two principal curiosity types reflected as a feeling of interest or of deprivation. The data for the study were collected from 670 volunteer middle-school students living in Ankara, in Turkey. The 6-point Likert-type original scale has eleven items with two subscales related to the feeling of interest (items 1, 4, 9 and 11) and deprivation (items 2, 3, 5, 6, 7, 8 and 10). The internal consistency of the original full scale and subscales as a feeling of interest and as a feeling of deprivation were proved reliable with findings of $0.80,0.74$ and 0.72 . A confirmatory factor analysis (CFA) of the original scale was performed with a two-factor model and showed wellfit indices. After a series of translation processes of the scale items into the Turkish language, the adapted scale was applied in three middle schools in Ankara. The adapted scale's descriptive statistics showed similar findings to the results of the original scale. The internal consistency of the adapted full scale and the subscales as a feeling of interest and as a feeling of deprivation were found to be $.92, .86$ and .88 . A CFA of the adapted scale was calculated using the same model of the original scale as a two-factor model and showed well-fit indices of .94 for CFI, .93 for TLI, .08 for RMSEA and .06 for SRMR, similar to the findings for the original scale. These statistical findings prove that the adapted scale items are valid and reliable for the Turkish language and culture within the scope of middle-school education in Turkey. The Turkish version of the LLCS can be tested using other variables for higher-level students in high schools and colleges.
\end{abstract}

(C) IJERE. All rights reserved

Keywords: Language learning curiosity, feeling of interest, feeling of deprivation

\section{INTRODUCTION}

Curiosity in general has many definitions but probably the best known is the instinctive tendency of human beings to use all the means available to strive to obtain knowledge for a wide variety of reasons. These reasons can sometimes emerge from someone's ambition to learn inquisitively or someone's purpose to avoid discomfort stemming from ignorance in a present situation (Kashdan et al., 2004). In other words, it is clear that the feeling of curiosity drives individuals to move forward to explore, to clarify unclear situations or just to satisfy their endless interests related to their instinct. The meaning and the source of curiosity have been widely discussed from the educational perspective. Students' academic performance can be affected by several variables such as curiosity and similar intrinsic motivational factors. From the educational point of view, curiosity results from a strong feeling of deprivation as the stimulus to learn something new or interesting (Hon-Keung et al., 2012). It can therefore be understood that curiosity in learners in the educational context might be regarded as a tool for getting out of an uncomfortable or ambiguous situation.

In the middle of the nineteenth century, curiosity was taken into consideration in two categories; epistemic curiosity and perceptual curiosity. Epistemic curiosity comes into play when there are uncertain situations or problems to be solved. It creates a desire in people to obtain information in order to solve a problem in a scientific way. Perceptual curiosity, on the other hand, drives an individual by the use of sensory stimulations purely to want to acquire new information (Berlyne, 1954,1957; Berlyne, 1958; Collins et al., 2004). These two categories push an individual in the same direction of learning the unknown, but the source of the activation to pursue knowledge rises either from an inner hunger or interest, or from environmental factors which need to be addressed or eliminated.

The sense of curiosity triggers learners to get on the track of information as a result of an endless ambition to understand or learn about every secret of the universe. Today, there are two curiosity theories; curiosity-driven theory and optimal arousal theory. Curiosity-driven theory refers to a curiosity which derives from a deep, uncomfortable and ambiguous situation, whereas optimal arousal theory has more motivational roots and a learner to pursue information to satisfy a feeling of pleasure and interest (Zelick, 2007). In a language-learning context, optimal arousal theory is more likely to happen for a child as a purely intrinsic curiosity drive because young learners depend on a precious aspect of spoken interactions and they learn a target language not only by listening but also by getting actively involved in conversations. Because children have a great amount of natural curiosity and a diligent enthusiasm to understand, they possess the most 
powerful need for learning a foreign language (Keijser et al., 2019). Curiosity in this context comes from a young learner's pure interest in learning. Students get involved by interaction and curiosity to acquire the target language and this can create a powerful source for learning effectively.

Within the theoretical background of curiosity, again there are two types of curiosity defined by Litman and Jimerson (2004) as interest and deprivation curiosity types. Interest curiosity (the I-type) derives from a learning stimulus which results in a positive feeling of interest. On the other hand, deprivation curiosity (the D-type) derives from a learning stimulus which results in the desire to avoid negative feelings. Individuals who are willing or interested in acquiring a foreign language generate a great deal of curiosity. The concepts of curiosity and foreign-language learning are integrated as language curiosity as a feeling of interest (LCFI) and language curiosity as a feeling of deprivation (LCFD) (Litman, 2007; Litman \& Jimerson, 2004; Mahmoodzadeh \& Khajavy, 2019).

In summary, curiosity is a significant element in the desire to gain a rewarding achievement in a learning atmosphere because it facilitates the concentration process of students while they are looking for new information deeply and eagerly. The feelings of every kind of curiosity help learners to access a desired goal such as information and wisdom. The effective achievement of the learning process happens fastest when there is an adequate level of curiosity (Uziana et al., 2017). The context of the language-learning field makes use of curiosity as a two-way approach explained as satisfying both the feeling of interest and the feeling of deprivation. LCFI derives from a learner's positive approach driven by interest: the learner willingly enjoys the process of acquiring the communicative skills of the target language. LCFD involves the need to acquire the information required in order to be efficient in the target language - in other words, to avoid the feeling of inefficiency. Both of these types of curiosity are invaluable for a foreign-language learner. Language learners sometimes seek information to feel the pleasure of learning to use the target language in a fluent way, but they might encounter a complex situation and feel unable to fill an information gap in the target language and it is this which generates a desire to get out of the uncomfortable context (Mahmoodzadeh \& Khajavy, 2019).

Mahmoodzadeh and Khajavy (2019) developed the language-learning curiosity scale (LLCS) for measuring language learners' curiosity level in terms of both concepts: language curiosity as a feeling of interest and language curiosity as a feeling of deprivation. The purpose of this study is therefore to adapt the LLCS for the Turkish language and culture for middle-school students. Two research questions were addressed in the process of adapting the original LLCS:

1. What is the adapted language learning curiosity scale's internal validity as a result of confirmatory factor analysis?

2. What is the adapted language learning curiosity scale's internal consistency as a result of reliability analysis?

\section{RESEARCH DESIGN and METHOD}

In this section, the language learning curiosity scale(LLCS) was explained in terms of adaptation process from the original scale into Turkish version. The whole adaptation process was carried out with a series of translation steps, application of the Turkish version of the scale and analysis. The research was performed by the use of survey research design. The researcher conducts a survey or a questionnaire mostly to a group of people as a sample so as to get information about their opinions, behaviours, attitudes and feelings about a certain topic or concept and analyse the data gathered in the light of some research questions and discuss them for the present or further studies (Creswell, 2002).

\section{Research Group}

The population of the present research consists of the middle school students who studies in Turkey and the sample group was determined with convenience sampling method which is described as affordable and easy to collect information and depending on the available people of the target population members for data gathering as a non-probability sampling method (Dornyei, 2007; Etikan et al., 2016). The sample group of the adaptation of language learning curiosity scale into Turkish language consists of 670 volunteer middle school students who lives in the capital city of Turkey. The data collection process was conducted in three middle schools in two months during the 2020-2021 Education Year. 428 (63.9\%) female and 242 (36.1\%) male students 
are the participants of the present study so as to enrol the data. The participant students' ages range from 10 to 15 in the present study. Moreover, there are $146(21.8 \%)$ students of 5 th grade, $190(28.4 \%)$ students of 6 th grade, 195 (29.1) students of 7 th grade and 139 (20.7) students of 8th grade.

\section{Instrument}

\section{Language Learning Curiosity Scale (LLCS)}

The original version of the language learning curiosity scale was developed by Mahmoodzadeh and Khajavy (2019) as a self-report questionnaire applied to 334 attendants of which 221 males and 113 females. The scale consists of 11 items of which 6 point Likert-type ranges from 1 (strongly disagree) to 6 (strongly agree) without a neutral option. What is more, there are two subscales of language learning curiosity scale as (a) language curiosity as a feeling of interest $(1,4,9,11$. items) and (b) language curiosity as a feeling of deprivation $(2,3,5,6,7,8,10$. items). The original LLCS's internal consistency was found as 0.80 and the subscales were detected as 0.72 for LCFD and 0.74 for LCFI. Internal consistency results show that the original LLCS and subscales are reliable so as to be utilized for language learning curiosity measurements.

\section{Adaptation Procedure}

The adaptation process of language learning curiosity scale has six stages. The following adaptation stages were constructed with the help of the adaptation survey of Adıgüzel and TatlıDalioğlu (2015):

1. The developers of the LLCS were communicated via e-mail in order to get allowance to adapt the original scale into Turkish language as a contribution to language learning literature and the required allowance was provided by the developers of the LLCS.

2. The original version of the scale was translated into Turkish language by two English teachers who are independent from each other. After that, the English teachers and the researchers of the survey came together in a meeting and determined a Turkish version of the scale items in common.

3. The Turkish version of the scale and the original scale were presented to a different group of four English language teachers who are independent from each other so as to get their opinions and comments about the translation of the scale items. The Turkish scale items were revised according to the opinions and comments of the four English teachers.

4. The revised version the scale was presented to a Turkish language teacher so as to determine the items' language coherence and accuracy in Turkish.

5. After the language processes of the scale were completed, the Turkish scale was presented to three curriculum and instruction experts, and a guidance and psychological counselling expert. The Turkish scale items were revised again in terms of the opinions of the experts.

6. The final Turkish draft of the LLCS was translated into English language in order to crosscheck the translation of the LLCS.

7. A detailed procedure of the adaptation of the scale was given to Republic of Turkey Ministry of Education because of the fact that the data collection process can only be performed with the allowance of formal authorities. The data collection process was completed with the students of three formal middle schools in the capital city of Turkey after the confirmation of the formal authorities.

Following the stages stated above the translated LLCS items were determined to be coherent in terms of language. There are two parts included in the data gathering document; the first part comprises of volunteers' gender, level of class and age variables and the second part includes the items of the language learning curiosity scale.

\section{Data Analysis}

There are two research questions to be answered in order to complete the adaptation of the LLCS into Turkish language. In order to detect the internal validity of the scale, confirmatory factor analysis was performed in a two-factor model by the use of AMOS 26. The reason of utilization of two-factor model is the original development process of the LLCS results show that the two-factor model indicates better fit indices than other factor models (Mahmoodzadeh \& Khajavy, 2019). The internal consistency of the adapted version of LLCS was analysed by the use of SPSS 22 version as a whole scale and sub-scales; LCFD, LCFI. There is a 
comparison of the results of the original and adapted LLCS in order to show the coherence of the versions with each other.

\section{RESULTS}

This section of the paper includes the results of confirmatory factor analysis, descriptive and reliability findings in the adaptation process of language learning curiosity scale for middle school students who study in Turkey.

A confirmatory factor analysis was conducted with a two-factor model in order to determine if the model is fit or not. There are some indices to be taken into consideration - cooperative fit index (CFI), TuckerLewis index (TLI), root mean square error of approximation (RMSEA), and root-mean-square residual (SRMR) - as a part of confirmatory factor analysis (Mahmoodzadeh \& Khajavy, 2019). The findings of the CFA is demonstrated in Table 1.

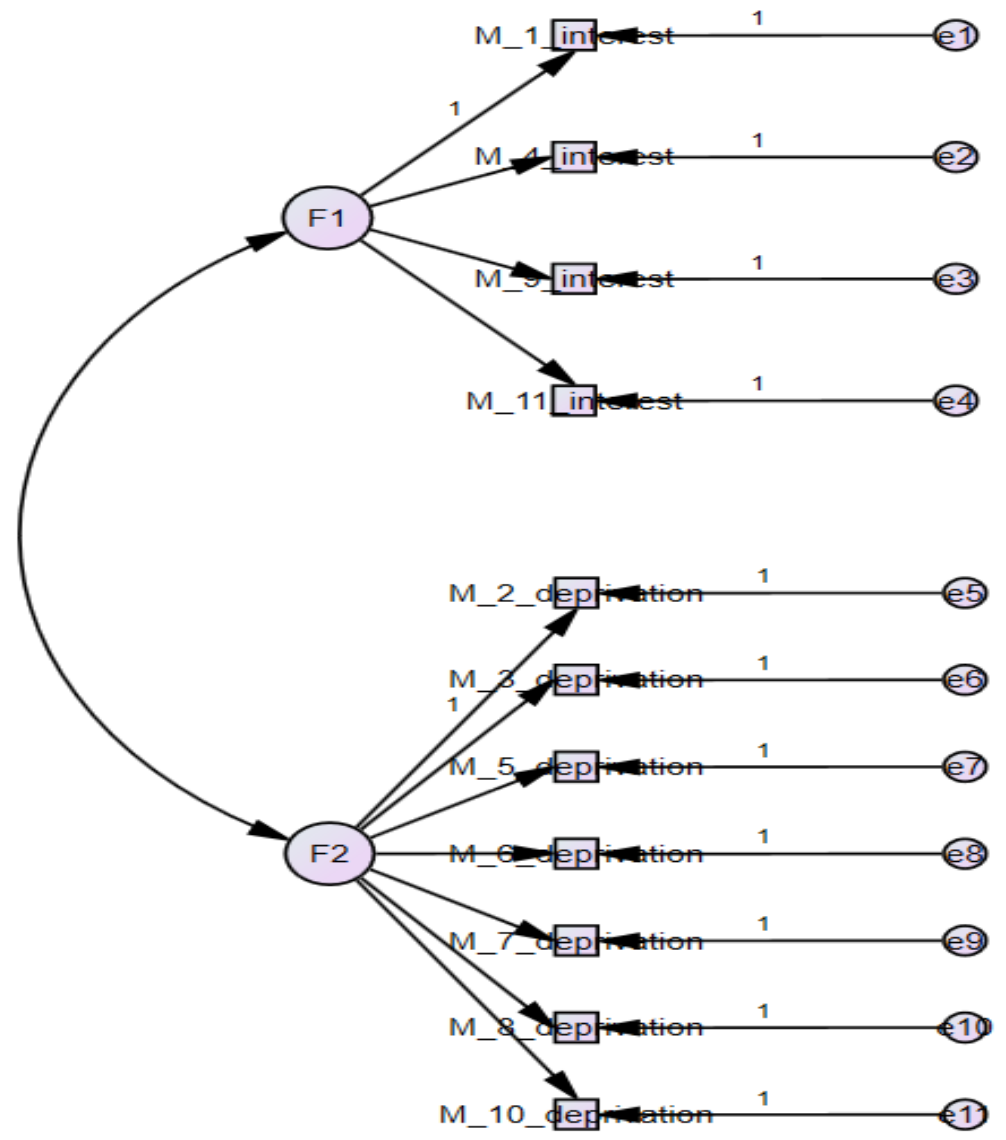

Figure 1. Two-factor Model of LLCS (Adapted Version)

Table 1: CFA Results of the Original and the Adapted Version of LLCS

\begin{tabular}{llcccccc}
\hline & $\chi 2$ & DF & CMIN/DF & CFI & TLI & RMSEA & SRMR \\
$\begin{array}{l}\text { Adapted } \\
\text { Version of }\end{array}$ & 268,88 & 43 & 6.25 & .94 & .93 & .08 & .06 \\
LLCS & & & & & & & \\
Original & 63.73 & 43 & 1.48 & .95 & .94 & .03 & .04 \\
$\begin{array}{l}\text { Version of } \\
\text { LLCS }\end{array}$ & & & & & & & \\
\hline
\end{tabular}


The confirmatory factor analysis findings of the adapted LLCS shows a fit model to be used for the Turkish students in the middle schools. The adapted LLCS's CFI, TLI, RMSEA and SRMR points reached highly acceptable values as .94, $.93, .08$ and .06 respectively because of the fact that CFI and TLI indices are appropriate over .90. Moreover RMSEA and SRMR points are convenient below .08 (Hu \& Bentler, 1999). The difference of CMIN/DF findings between the adapted and the original versions of the scale shows that the adapted version's CMIN/DF finding does not fit the model adequately. Because the accepted level for the CMIN/DF statistic is lower than 5 (Marsh \& Hocevar, 1985; Moss et al., 2015). CMIN/DF value of the adapted version of LLCS is explained as valid finding with the sources in the conclusion part of the paper.

The internal consistency of the adapted version of LLCS was calculated in terms of mean, standard deviation and reliability parameters. The descriptive and reliability findings of the scales are demonstrated in Table 2.

Table 2: Descriptive and Reliability Findings of LLCS

\begin{tabular}{|c|c|c|c|c|c|}
\hline & & Item Numbers & Mean & St. Deviation & Cronbach's A. \\
\hline $\begin{array}{l}\text { Total } \\
\text { LLCS }\end{array}$ & Adapted & 11 & 4.69 & 1.02 & .92 \\
\hline LCFI & & 4 & 4.94 & 1.09 & .86 \\
\hline LCFD & & 7 & 4.55 & 1.04 & .88 \\
\hline $\begin{array}{l}\text { Total } \\
\text { LLCS }\end{array}$ & Origina 1 & 11 & 4.95 & 0.71 & .80 \\
\hline LCFI & & 4 & 5.44 & 0.78 & .74 \\
\hline LCFD & & 7 & 4.45 & 0.86 & .72 \\
\hline
\end{tabular}

The adapted LLCS's descriptive and reliability results are taken into consideration with the subscales and comparatively with the original scale's statistics. First descriptive statistical findings which are about mean scores of the adapted LLCS and its subscales as LCFI and LCFD are detected 4.69, 4.94 and 4.55 respectively. According to these results, it is clear that language learning curiosity level is frequent among middle school students in Turkey. Moreover, as the highest mean score is found for LCFI proves that language learning curiosity source of the middle school students derives from more the feeling of interest than the feeling of deprivation. The adapted total scale points, LCFI and LCFD subscale points of internal consistency was calculated with Cronbach Alpha and found as $.92, .86$ and .88 respectively. As a result of these score points, the adapted scale and subscales are testified to be reliable for the Turkish language and culture in terms of middle school students. The values of the adapted and the original scales and subscales demonstrated in Table 2 are similar to each other so the adapted version of the scale is proven to be a reliable tool to be used in Turkish language.

\section{CONCLUSION}

The main aim of this research is to make a contribution to knowledge about curiosity in the context of acquiring a new language by adapting the LLCS for the Turkish language. Language learners' interest of inquiry base and ambition to acquire a new language in all aspects are the two variables forming the subs cales of the LLCS. In order to adapt the LLCS, its items were processed in a series of translation stages with the help of several language teachers, curriculum developers and guidance-psychological counselling experts. The adapted scale's validity and reliability analyses were carried out using CFA with AMOS, Cronbach's Alpha and other descriptive statistical measurements.

As the original version of the LLCS was developed as a two-factor model with good-fit statistics, the adaptation analysed in the present study involved the same two-factor model with good-fit statistical results and the internal validity of the adapted scale was proved to be acceptable. As a result of the reliability analysis, both the adapted scale and its subscales were found to have similar statistical characteristics to those of the 
original scale. The adapted version of the LLCS's CMIN/DF value of 6.25 was not lower than the acceptable level of 5. Moreover the difference in CMIN/DF findings between the adapted and the original versions of the scale shows that the adapted version's CMIN/DF finding did not fit the model adequately. Fortunately, Bergh (2015) stated that chi-square findings are sensitive to sample size, which means that they are not reliable (Mwansisya et al., 2021;Xia \& Yang, 2018). There is a big difference in sample sizes between the original (334 participants) and the adapted (670 participants) versions of LLCS. This significant difference in sample sizes proves that the adapted version of the LLCS is appropriate for middle-school students in Turkey. In other words, the adapted scale and subscales showed reliable evidence for their use in the Turkish context.

Studies of curiosity have been carried out in other learning fields. Üstün (2019) found a positive correlation between curiosity and a lifelong-learning tendency among university students. Although the current study was not designed as a correlational survey, it is completely related to language-learning field. Moreover, the middle-school students' language-learning curiosity level was found to be high, as demonstrated by the mean value (4.69) of the total scale. The concept of curiosity is therefore a potential correlational variable to be researched further in terms of the wider language-learning field. There is a relationship between curiosity and instruction strategies in respect of learners' reading comprehension success (Uziana et al., 2017). The LLCS has also been found to be a valid and reliable instrument for use in correlational studies. Learners' language skill areas could therefore be examined in terms of curiosity and different descriptive variables.

Tulgar (2018) found that learners' language improvement and acquisition were facilitated by curiosity. In the current study, the mean value of the language-learning curiosity level of the middle-school students was found to 4.69, so it is possible that their language-learning development was as high as their curiosity level in language learning. It is suggested that future researchers could study these variables in order to confirm the possible hypothesis.

Karademir et al. (2019) surveyed pre-service teachers and found that their curiosity level had a medium value and that there was a meaningful correlation between the inquiry skills and curiosity levels of the teachers. In the current LLCS survey, however, the language-learning curiosity level of middle-school students was found to be higher than the medium level of the scale. A positive relationship between inquiry skills and curiosity levels suggests that there is a need for future studies to focus more on the correlations between inquiry and curiosity.

In conclusion, the statistical findings reported above have shown that the adaptation of the original version of the LLCS for the Turkish language and culture especially for middle-school students has well-fit validity and reliability. The limitations of this study are related to global health conditions, the sampling method used and the participants' class level. The data collection process of this survey was performed successfully in spite of restrictive Covid-19 conditions with the help of the school teachers and managers; the data were gathered in three middle schools in the capital city of Turkey using convenience sampling, and middle-school students were used as the samplegroup. Other educational levels such as high-school students and university students could be included in future studies in order to confirm the validity and reliability findings of the LLCS in different educational contexts. Furthermore, the language-learning curiosity variable could be examined in terms of other language-learning influences such as motivation, attitude and willingness, as was done in the research leading to the development of the original scale.

\section{REFERENCES}

Adıgüzel, C., \& TatlıDalioğlu, S. (2015). Study on Turkish adaptation of new teacher possible selves questionnaire. Electronic Journal of Social Sciences, 14(53), 173-185.

Bergh, D. (2015). Chi-squared test of fit and sample size-a comparison between a random sample approach and a chi-square value adjustment method. Journal of Applied Measurement, 16(2), 1-14.

Berlyne, D. E. (1954). A theory of human curiosity. British Journal of Psychology, 45(3), 180.

Berlyne, D. E. (1957). Conflict and information-theory variables as determinants of human perceptual curiosity. Journal of Experimental Psychology, 53(6), 399.

Berlyne, D. E. (1958). The influence of complexity and novelty in visual figures on orienting responses. Journal of Experimental Psychology, 55(3), 289. 
Collins, R. P., Litman, J. A., \& Spielberger, C. D. (2004). The measurement of perceptual curiosity. Personality and Individual Differences, 36(5), 1127-1141.

Creswell, J. W. (2002). Educational research: planning, conducting, and evaluating quantitative. Prentice Hall Upper Saddle River, NJ.

Dornyei, Z. (2007). Research methods in applied linguistics. Oxford University Press.

Etikan, I., Musa, S. A., \& Alkassim, R. S. (2016). Comparison of convenience sampling and purposive sampling. American Journal of Theoretical and Applied Statistics, 5(1), 1-4.

Hon-Keung, Y., Man-shan, K., \& Lai-fong, C. A. (2012). The impact of curiosity and external regulation on intrinsic motivation: an empirical study in Hong Kong Education. Online Submission, 2(5), 295-307.

Hu, L. t., \& Bentler, P. M. (1999). Cutoff criteria for fit indexes in covariance structure analysis: conventional criteria versus new alternatives. Structural Equation Modeling: A Multidisciplinary Journal, 6(1), 1-55.

Karademir, Ç. A., Çaylı, B., \& Deveci, Ö. (2019). An investigation of pre-service teachers' inquiry skills and curiosity levels. Elementary Education Online, 18(3), 1157-1171.

Kashdan, T. B., Rose, P., \& Fincham, F. D. (2004). Curiosity and exploration: facilitating positive subjective experiences and personal growth opportunities. Journal of Personality Assessment, 82(3), 291-305. https://doi.org/10.1207/ s15327752jpa8203_05

Keijser, D., Gelderloos, L., \& Alishahi, A. (2019). Curious topics: A Curiosity-based model of first language word learning. In Proceedings of the 41st Annual Conference of the Cognitive Science Society

Litman, J. A. (2007). Curiosity as a feeling of interest and feeling of deprivation: the i/d model of curiosity. Issues in the Psychology of Motivation, 149-156.

Litman, J. A., \& Jimerson, T. L. (2004). The measurement of curiosity as a feeling of deprivation. Journal of Personality Assessment, 82(2), 147-157.

Mahmoodzadeh, M., \& Khajavy, G. H. (2019). Towards conceptualizing language learning curiosity in SLA: an empirical study. Journal of Psycholinguistic Research, 48(2), 333-351.

Marsh, H. W., \& Hocevar, D. (1985). Application of confirmatory factor analysis to the study of self-concept: first-and higher order factor models and their invariance across groups. Psychological Bulletin, 97(3), 562.

Moss, T. P., Lawson, V., \& White, P. (2015). Identification of the underlying factor structure of the derriford appearance scale 24. PeerJ, 3, e1070.

Mwansisya, T., Mbekenga, C., Isangula, K., Mwasha, L., Pallangyo, E., Edwards, G., Orwa, J., Mantel, M., Mugerwa, M., \& Subi, L. (2021). Translation and validation of training needs analysis questionnaire among reproductive, maternal and newborn health workers in Tanzania. BMC Health Services Research, 21(1), 1-12.

Tulgar, A. T. (2018). The Effects of curiosity on second language learning in terms of linguistic, social-cultural and pragmatic development. Adnan Menderes Üniversitesi Ĕ̆itim Fakültesi Eğitim Bilimleri Dergisi, 9(2), 59-72.

Uziana, U., Sibarani, B., \& Pulungan, A. H. (2017). The effect of teaching strategies and curiousity on students' reading comprehension achievement. Linguistik Terapan, 14(2), 182-193.

Üstün, A. N. (2019). Ciddivekayıtsız boş zaman katılımcısı üniversite öğrencilerinin meraklılık ve yaşam boyu öğrenme eğilimi. Publication Number 559309, Gazi Üniversitesi.

Xia, Y., \& Yang, Y. (2018). The influence of number of categories and threshold values on fit indices in structural equation modeling with ordered categorical data. Multivariate Behavioral Research, 53(5),731755.

Zelick, P. R. (2007). Issues in the psychology of motivation. Nova Publishers. 


\section{Appendix 1}

\begin{tabular}{|c|c|c|c|c|c|c|c|}
\hline & $\begin{array}{l}\text { Dil Öğrenme Merak Ölçeği } \\
\text { (Language Learning Curiosity Scale) }\end{array}$ & 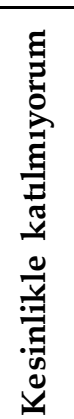 & 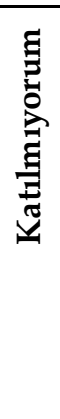 & 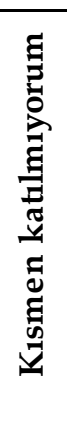 & 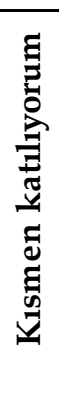 & 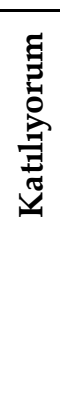 & 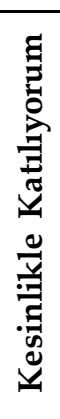 \\
\hline 1 & $\begin{array}{l}\text { Günlük hayatta İngilizceyi nasıl konuşacağımı } \\
\text { merak ediyorum. }\end{array}$ & & & & & & \\
\hline 2 & $\begin{array}{l}\text { İngilizce dil bilgisi kurallarını ve kural dışı } \\
\text { durumlarını öğrenmeyi seviyorum. }\end{array}$ & & & & & & \\
\hline 3 & $\begin{array}{l}\text { İngilizceyle ilgili aklıma takılan herhangi bir şeyi } \\
\text { öğrenmeden rahat edemiyorum. }\end{array}$ & & & & & & \\
\hline 4 & $\begin{array}{l}\text { Bir İngiliz ile İngilizceyi ne kadar iyi konuşacağımı } \\
\text { merak ediyorum. }\end{array}$ & & & & & & \\
\hline 5 & $\begin{array}{l}\text { Türkçe ile İngilizce arasındaki kültürel farklılıkları } \\
\text { öğrenmeyi seviyorum. }\end{array}$ & & & & & & \\
\hline 6 & $\begin{array}{l}\text { İngilizceyi, İngilizce öğretmenim gibi konuşup } \\
\text { yazmanın nasıl bir duygu olduğunu merak } \\
\text { ediyorum. }\end{array}$ & & & & & & \\
\hline 7 & $\begin{array}{l}\text { İngilizce dersinde cevabım yanlış olduğunda bunun } \\
\text { sebebini merak ediyorum. }\end{array}$ & & & & & & \\
\hline 8 & $\begin{array}{l}\text { Anlamını bilmediğim İngilizce bir kelime için } \\
\text { hemen sözlüğe bakarım ya da kelimeyi } \\
\text { öğretmenime sorarım. }\end{array}$ & & & & & & \\
\hline 9 & $\begin{array}{l}\text { İngilizceyi bir İngiliz gibi akıcı konuşmanın nasıl bir } \\
\text { duygu olduğunu merak ediyorum. }\end{array}$ & & & & & & \\
\hline 10 & $\begin{array}{l}\text { Türkçe bildiğim bir şeyi İngilizce olarak } \\
\text { anlatamayınca öğrenmek için daha çok } \\
\text { uğraşıyorum. }\end{array}$ & & & & & & \\
\hline 11 & $\begin{array}{l}\text { Yeni öğrendiğim İngilizce kelimeleri günlük } \\
\text { hayatımda kullanmak hoşuma gidiyor. }\end{array}$ & & & & & & \\
\hline
\end{tabular}

